\title{
Enraizamento de estacas de cajazeira (Spondias mombin L.) em função da aplicação de reguladores vegetais
}

\section{Rooting of yellow mombin cuttings (Spondias mombin L.) as a function of the application of plant regulators}

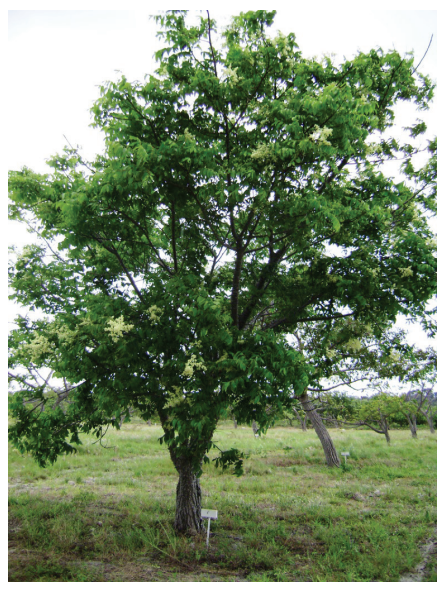

\section{MÁRIO LENO MARTINS VÉRAS 1,4 \\ REJANE MARIA NUNES MENDONÇA² \\ CHRISTIANE MENDES CASSIMIRO RAMIRES ${ }^{3}$ \\ VANDEILSON LEMOS DE ARAÚJO2 \\ LUCIMARA FERREIRA DE FIGUEREDO² \\ LUNARA DE SOUSA ALVES ${ }^{2}$ \\ WALTER ESFRAIN PEREIRA ${ }^{2}$}

Acesso de cajazeira do Banco ativo de Germoplasma (BAG) na Empresa Estadual de Pesquisa Agropecuária da Paraíba (EMEPA), João Pessoa-PB.

Foto: C.M.C. Ramires

\section{RESUMO}

Até o momento não há cultivos comercias de cajazeira no Brasil, sendo os frutos colhidos de plantas em cultivo extrativistas. Uma das causas disso é a falta de um protocolo de propagação desta espécie, pois a cajazeira apresenta baixo percentual de enraizamento de estacas. Sendo assim, técnicas que proporcionem o máximo enraizamento das estacas são de extrema relevância. O trabalho tem por objetivo avaliar o efeito do tratamento da planta matriz com zinco sobre o enraizamento de estacas de cajazeira tratadas com ácido indolbutírico. No experimento foi adotado o delineamento inteiramente casualizado, com 9 tratamentos, em arranjo experimental com níveis pré-determinados para os fatores, pela matriz "Composto Central de Box" referente as concentrações de zinco $\left(0 ; 5,8 ; 20 ; 34,2\right.$ e $\left.40 \mathrm{mg} \mathrm{L}^{-1}\right)$ e combinações com as concentrações de ácido indolbutírico $\left(0 ; 872,35 ; 3.000 ; 5.127,65\right.$ e $\left.6.000 \mathrm{mg} \mathrm{L}^{-1}\right)$ com 4 repetições, onde cada unidade experimental foi constituída por 12 estacas. A aplicação de zinco em plantas matrizes de cajazeira não apresenta efeito sobre o enraizamento de estacas. A dose de $6.000 \mathrm{mg} \mathrm{L}^{-1}$ de ácido indolbutírico proporciona um incremento nas brotações, estacas vivas com calo, no entanto, não influencia no enraizamento.

Palavras-chave adicionais: propagação vegetativa; ácido indolbutírico; zinco; frutas tropicais.

Universidade Federal de Viçosa, Departamento de Fitotecnia, Viçosa (Brasil). ORCID Véras, M.L.M.: 0000-0001-5968-4564

2 Universidade Federal da Paraíba, Departamento de Fitotecnia e Ciências Ambientais, Centro de Ciências Agrárias, Areia (Brasil). ORCID Mendonça, R.M.N.: 0000-0002-2594-6607; ORCID Araújo, V.L.: 0000-0001-6641-9814; ORCID Figueredo, L.F.: 0000-0002-4372-9884; ORCID Alves, L.S: 0000-0002-5049-7081; ORCID Pereira, W.E.: 0000-0003-10850191

3 Empresa Estadual de Pesquisa Agropecuária, João Pessoa (Brasil). ORCID Ramires, C.M.C.: 0000-0002-0751-865X

4 Corresponding author. mario.veras1992@gmail.com 


\section{ABSTRACT}

At the moment, there are no commercial yellow mombin crops in Brazil, where fruits are harvested from extractive crops. One reason for this is the lack of a propagation protocol for this species because the yellow mombin has a low rooting percentage for cuttings. Therefore, techniques that provide maximum rooting for cuttings are required. The objective of this study was to evaluate the effect of a matrix plant treatment with zinc on the rooting of yellow mombin cuttings treated with indolebutyric acid. In this experiment, a completely randomized design was used, with 9 treatments arranged with pre-determined levels for the factors with the matrix "Central Box Compound" for the zinc concentrations $\left(0,5.8,20,34.2\right.$ and $\left.40 \mathrm{mg} \mathrm{L}^{-1}\right)$ and combinations with the indolbultric acid concentrations $\left(0 ; 872.35 ; 3,000 ; 5,127.65\right.$ and $\left.6,000 \mathrm{mg} \mathrm{L}^{-1}\right)$, with 4 replicates, where each experiment unit consisted of 12 cuttings. The application of zinc in yellow mombin matrix plants had no effect on the rooting of cuttings. The $6,000 \mathrm{mg} \mathrm{L}^{-1}$ indolebutyric acid dose provided an increase in sprouts and live cuttings with a callus; however, it did not influence the rooting.

Additional key words: vegetative propagation; indolebutyric acid; zinc; tropical fruits.

Data de recepção: 29-05-18 Aprovado para publicação: 30-11-2018

\section{INTRODUÇÃO}

A cajazeira (Spondia mombin L.) é uma planta de clima tropical, pertencente ao gênero Spondias e a família das Anacardiáceaes. No Brasil, está presente em todas as regiões, contudo, não há cultivos comerciais desta espécie (Araújo et al., 2014). Os frutos da cajazeira são muito consumidos, em virtude de serem ricos em compostos bioativos, com alto potencial antioxidante, agregando valor a esses frutos (Silva et al., 2012; Neves et al., 2015).

Na propagação desta espécie, comumente o método mais adotado é a estaquia, visto que proporciona plantas homogêneas e produção precoce invés da propagação via seminífera que ocasiona germinação desuniforme e produção demorada. Contudo, assim como as demais espécies do Spondias, algumas plantas apresentam dificuldade de enraizamento, sendo esse obstáculo ocasionado na maioria das vezes pelo balanço hormonal da planta matriz (Costa et al., 2015).

Para o enraizamento ocorrer, precisa-se de concentrações endógenas de auxina necessárias para estimular a formação de raízes (Meneguzzi et al., 2015). A auxina está entre os hormônios vegetais mais importantes para o enraizamento de estacas, sendo o ácido indolbutírico (AIB) o mais conhecido e um dos mais eficientes e usados na propagação via estaquia, uma vez que é foto estável e imune à ação biológica (Figueiredo et al., 2009; Alcantara et al., 2010).

Alguns trabalhos com o uso de ácido indolbutírico na propagação via estaquia em Spondias tem mostrado que as espécies desse gênero apresentam baixo enraizamento (Véras et al., 2017; Véras et al., 2018), a exemplo de Souza y Lima (2005), em cajazeira, utilizando ramos apicais para confecção das estacas e aplicação de concentrações de AIB, obtiveram 8,3 a $23,3 \%$ de estacas enraizadas. Paula et al. (2007) que observaram baixo percentual de enraizamento de estacas lenhosas e herbáceas de umbuzeiro e observaram percentual de 33,3\% de estacas herbáceas enraizadas, com a aplicação da dose de $500 \mathrm{mg} \mathrm{L}^{-1}$ de AIB imersas por $10 \mathrm{~min}$. Rios et al. (2012) em umbuzeiro com estacas de $20 \mathrm{~cm}$ de comprimento, tratadas com AIB (6000 mg L-1) verificaram baixo percentual de enraizamento $(33,33 \%)$.

Além disso, um fator extremamente relevante para o enraizamento é a nutrição da planta matriz, uma vez que o estado nutricional da planta determina as respostas morfogenéticas como a formação de raízes adventícias, bem como, a modulação do comprimento e densidade das mesmas. Sendo assim, é essencial que a planta matriz esteja em balanço nutricional adequado (Cunha et al., 2009). Dentre os elementos minerais importantes para o enraizamento, o zinco é essencial, visto que participa da rota do triptofano, aminoácido precursor da auxina. Apesar disso há poucos estudos com o uso de zinco como cofator importante no enraizamento, podendo até mesmo substituir a utilização de auxinas sintéticas (Nicoloso et al., 1999).

Em virtude da carência de estudos relacionados à propagação da cajazeira, além do baixo percentual de 
enraizamento desta espécie o tratamento de planta matriz pode ser alternativa viável, para elevar o enraizamento. Neste sentido, o presente trabalho objetivou avaliar o efeito do tratamento da planta matriz com zinco sobre o enraizamento de estacas de cajazeira tratadas com ácido indolbutírico.

\section{MATERIAL E MÉTODOS}

O experimento foi conduzido no período de julho a novembro de 2016 no viveiro de Fruticultura, pertencente à Universidade Federal da Paraíba no município de Areia-PB, situada nas coordenadas geográficas 6 51'47" e $7^{\circ} 02^{\prime} 04^{\prime \prime}$ latitude Sul e longitude Oeste $35^{\circ} 34^{\prime} 13^{\prime \prime}$ e $35^{\circ} 48^{\prime} 28^{\prime \prime}$ do meridiano de Greenwich. Foram selecionados ramos lenhosos de plantas de cajazeira (Spondias mombin sp.), provenientes da estação experimental da Empresa Brasileira de Pesquisa Agropecuária (EMEPA), João Pessoa-PB. As plantas matrizes de cajazeira foram obtidas de enxertia, com idade de 10 a 20 anos.

No ensaio utilizou-se o delineamento inteiramente casualizado, com nove tratamentos, e níveis pré-determinados pela matriz "Composto Central de Box" referente as doses de zinco, combinadas com as doses de AIB, com quatro repetições, cada unidade experimental constituída por 12 estacas no total.

O tratamento com zinco foi formulado por meio do produto comercial (Maxizinco ${ }^{\circledR}$, Agrichem), aplicado via pulverização nas plantas matrizes $7 \mathrm{~d}$ antes da retirada dos ramos. As doses de zinco correspondentes aos tratamentos $\left(0 ; 5,8 ; 20 ; 34,2\right.$ e $\left.40 \mathrm{mg} \mathrm{L}^{-1}\right)$ foram diluídas conforme a indicação comercial do produto de $1.000 \mathrm{~g} \mathrm{~L}^{-1}$ de zinco, encontrando-se a partir da mesma a dose específica para cada tratamento. O zinco foi diluído dentro de um pulverizador costal e aplicado na copa das plantas de umbuzeiro com volume aproximado de $4 \mathrm{~L}$.

Sete dias após a aplicação do zinco, foram coletados ramos de cajazeira com 3 a 4 mm de diâmetro e aproximadamente $30 \mathrm{~cm}$ de comprimento, sendo acondicionados em papel umedecido, colocados em sacos plásticos e transportados para o Viveiro de Fruticultura na Universidade Federal da Paraíba, município de Areia-PB, Brasil. Estes foram levados para a câmara de nebulização onde realizou-se o corte das estacas, sendo a parte superior cortada reta e a basal cortada em bisel, ficando com $20 \mathrm{~cm}$ de comprimento (Véras et al., 2017; Véras et al., 2018b).
A solução hidroalcoólica do AIB foi preparada pela pesagem de $872,35 \mathrm{mg} \mathrm{L}^{-1}$ de AIB e dissolvidos em 50 $\mathrm{mL}$ de álcool 96 $6^{\circ}$ em um Becker. Após totalmente dissolvido, completou-se o volume para $1.000 \mathrm{~mL}$, com água destilada, obtendo-se então a concentração de $872,35 \mathrm{mg} \mathrm{L}^{-1}$ de AIB; sendo repetido esse mesmo procedimento para as demais doses utilizadas $(0,872.35$, $3.000,5.127,65$ e $6.000 \mathrm{mg} \mathrm{L}^{-1}$ ).

Após o término do preparo, as estacas foram agrupadas, por repetição e tiveram $1,0 \mathrm{~cm}$ da base colocada na solução hormonal por $5 \mathrm{~s}$, conforme cada tratamento. Posteriormente, realizou-se o plantio em tubetes com diâmetro interno de $26 \mathrm{~mm}$ e diâmetro externo de $33 \mathrm{~mm}$ e volume de $55 \mathrm{~cm}^{3}$, preenchidos com substrato formado de areia e composto orgânico, na proporção 1:1 (v/v); sendo submetido a $50 \%$ de luz solar em estufa sob nebulização, com abertura de $10 \mathrm{~s}$ e intervalos de $15 \mathrm{~min}$.

Aos 90 d após a instalação do experimento foram avaliados: o percentual estacas brotadas, o comprimento das brotações, o diâmetro das brotações, o percentual de estacas enraizadas, o percentual de estacas vivas com e sem calo, o percentual de estacas mortas, o número de raízes por estaca, o comprimento da raiz, a massa seca das raízes, folha e a massa seca total.

Os resultados foram submetidos à análise de variância pelo Teste $\mathrm{F}(P \leq 0,05)$. Para as variáveis com efeito da interação significativa foram ajustadas a superfície de resposta, e caso contrário foi feito a análise de regressão polinomial. As análises foram realizadas com o software estatístico SAS (Cody, 2015).

\section{RESULTADOS E DISCUSSÃO}

Não houve efeito significativo para o percentual de estacas brotadas, número de brotações, comprimento e diâmetro de brotações, percentual de estacas enraizadas, de estacas vivas com e sem calo, estacas mortas, comprimento da raiz, número de raízes, massa seca da raiz, folha e total quando relacionada às concentrações de zinco, apresentando valores médios de $41,48 \% ; 1,18 ; 3,32 \mathrm{~cm} ; 2,17 \mathrm{~mm} ; 25,92 \% ; 9,7 \% ; 9,7 \%$; $22,22 \% ; 3,39$ cm; 1,58 raízes; 2,99 g; 4,8 g e 12 g, respectivamente (dados não apresentados).

O percentual de estacas brotadas (Fig. 1A) se ajustou a equação linear com tendência decrescente, apresentando redução com o aumento das concentrações de AIB, onde o máximo estimado (61\%) foi observado 
sem aplicação de AIB (0 mg L-1), evidenciando que a formação de brotações é afetado negativamente pelo ácido indolbutirico, além disso, o excesso de formação de brotações pode ocasionar efeito negativo em virtude do desvio de reservas para o enraizamento (Véras et al., 2017; Véras et al., 2018).

Para efeito das concentrações de ácido indolbutírico, constatou-se que o número de brotações (Fig. 1B), comprimento (Fig. 1C) e diâmetro de brotações (Fig. 1D) mostraram tendência quadrática com as concentrações de AIB, observando-se incrementos de $30,76 \%$ (Fig. 1B), 43,06\% (Fig. 1C) e 3,83\% (Fig. 1D) quando as estacas foram tratadas com $6.000 \mathrm{mg} \mathrm{L}^{-1}$ de AIB em comparação com o tratamento controle, respectivamente.

Esses resultados foram superiores aos observados por Lima et al. (2002) que trabalhando com estaquia em umbu-cajazeira (Spondias sp.), obtiveram 30\% de estacas brotadas. Os estudos com tratamento em plantas matrizes com zinco são muito incipientes, além disso, são muito escassas as informações sobre tratamentos da planta matriz com zinco em Spondias.

Corroborando com os observados por Tosta et al. (2012) em estacas de cajaraneira, onde constataram um aumento no número de brotações (2,9 brotações), à medida que se aumentou a concentração de AIB até $3.500 \mathrm{mg} \mathrm{L}^{-1}$, com decréscimo posterior.

Em relação ao comprimento de brotações (Fig. 1C), os resultados supracitados corroboram com os apresentados por Tosta et al. (2012) que constataram um aumento no comprimento das brotações de cajaraneira, à medida que se aumentou a concentração de AIB; no entanto obtiveram maior comprimento que o apresentado no presente ensaio, com valor máximo de $5,6 \mathrm{~cm}$ na concentração de $3.045 \mathrm{mg} \mathrm{L}^{-1}$ de AIB. Ao trabalharem com cajazeira, Gomes et al. (2005) constataram que o uso de AIB aumentou o comprimento das brotações das estacas.

Um dos aspectos negativos da formação de brotações é a redução que pode ocasionar no enraizamento, quando as reservas da estaca são utilizadas para esta finalidade, em detrimento do enraizamento. Porém, quando há tempo suficiente para que estas possam produzir auxinas e enviar para a base da estaca, num movimento basípeto, favorecem o enraizamento (Véras et al., 2017; Véras et al., 2018).

Observou-se que os percentuais de estacas vivas com calo (Fig. 1E) e estacas mortas (Fig. 1F) foram significativamente influenciados e, conforme as equações de regressão observa-se haver resposta quadrática, sendo estimados os percentuais máximos de estacas vivas com calo $(37,5 \%)$ e estacas mortas $(56,25 \%)$ nas estacas sem AIB ( $\left.0 \mathrm{mg} \mathrm{L}^{-1}\right)$, apresentando, a partir desta concentração tendência de decréscimo de 33,3\% e $22,22 \%$ no percentual de estacas vivas com calo e estacas mortas, respectivamente, quando as estacas foram tratadas com maior a concentração de AIB (6.000 $\mathrm{mg} \mathrm{L}^{-1}$ ) comparado com as estacas sob $0 \mathrm{mg} \mathrm{L}^{-1}$ de AIB.

Em amoreira preta, Yamamoto et al. (2013) não verificaram diferença significativa para o percentual de estacas enraizadas quando as estacas foram tratadas com AIB. Nacata et al. (2014), em estacas de caramboleira, constataram que a porcentagem enraizamento, de calejamento e de sobrevivência, apresentaram diferença significativa, na qual a concentração de 100 $\mathrm{mg} \mathrm{L}^{-1}$ de AIB apresentou os melhores resultados para estas variáveis.

Sabião et al. (2011), em Passiflora nitida observaram que a porcentagem de sobrevivência de estacas não diferiram significativamente quando foi aplicado o AIB, contudo, a concentração máxima (5.000 mg L-1) apresentou valores superiores (87,69\% de sobrevivência). Enquanto que para a porcentagem de enraizamento constataram que houve diferença significativa, obtendo $87,69 \%$ de enraizamento na concentração de $5.000 \mathrm{mg} \mathrm{L}^{-1}$.

Em outros trabalhos diversos autores também não obtiveram resultados significativos com a aplicação de AIB sobre a sobrevivência das estacas, em estacas de hibisco (Souza et al., 2015), umbuzeiro (Véras et al., 2018a; Véras et al., 2018b) e umbu cajazeira (Véras et al., 2018c). Gomes et al. (2005) também não constataram efeito significativo das doses de AIB no enraizamento de estacas de umbu-cajazeira.

O uso da estaquia depende da habilidade de formação de raízes de cada espécie e/ou cultivar, além disso, a qualidade do sistema radicular é um aspecto muito importante, uma vez que a baixa qualidade do sistema radicular desfavorecerá as mudas quando forem plantadas. Outrossim, a aplicação de auxina exógena como estratégia de favorecer o enraizamento também depende da espécie ou cultivar e da concentração de auxina existente no tecido. Sendo assim, a quantidade que deve ser utilizada varia conforme espécie, populações ou clones (Peña et al., 2012).

Um dos fatores que pode ter influenciado na não significância é o balanço hormonal endógeno, já que 

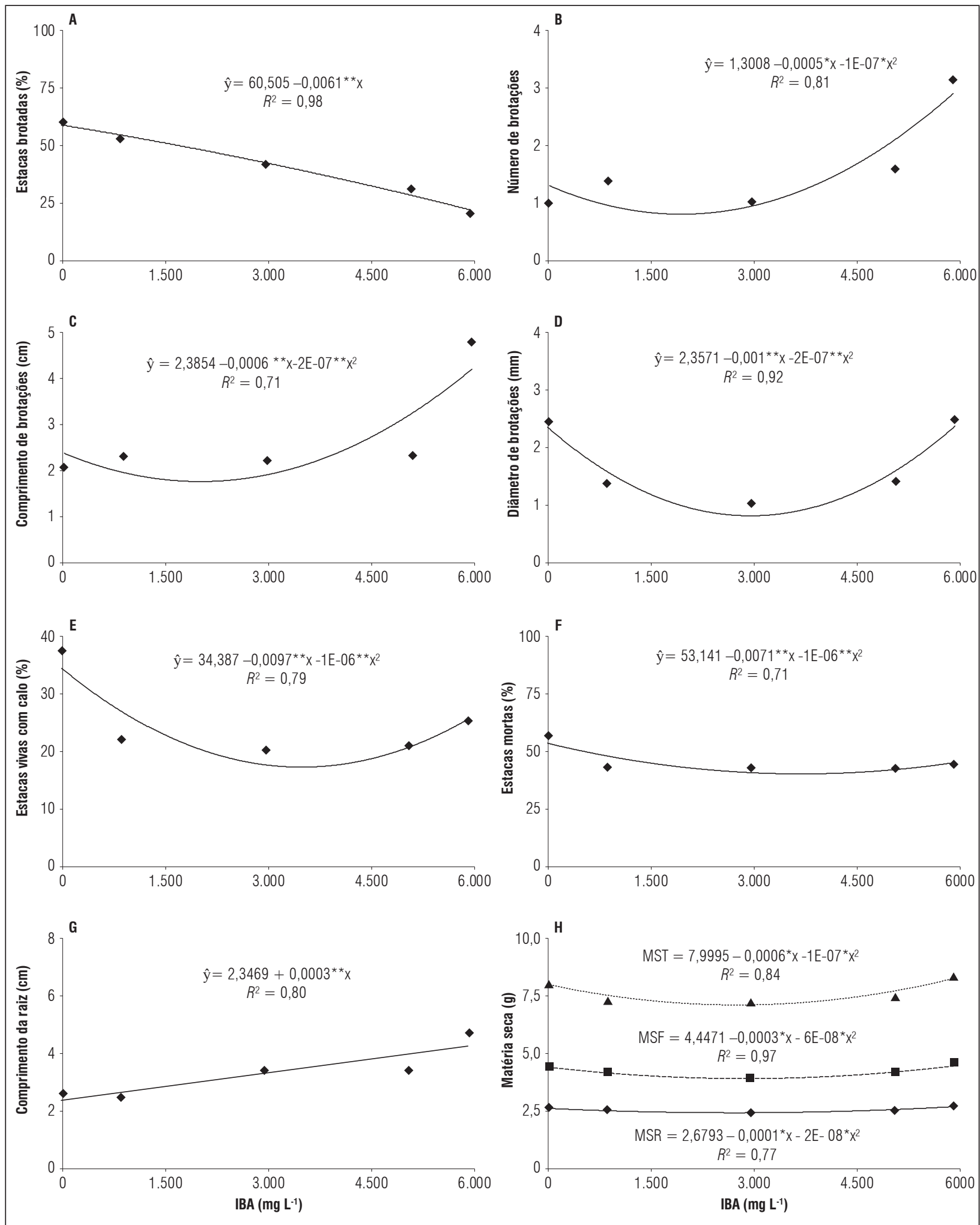

Figura 1. Percentual de estacas brotadas (A), número de brotações por estacas (B), comprimento de brotações (C), diâmetro de brotações (D), estacas mortas (E) e número de raízes por estaca (D) de umbu-cajazeira em função do tratamento com doses de AIB. Massa seca da raiz (MSR), folha (MSF) e total (MST). * significativa $P<0,05 ;{ }^{* *}$ significativa $P<0,01$. 
para ocorrer o enraizamento é preciso que haja equilíbrio nos teores endógenos de auxinas, giberelinas e citocininas, além disso, a concentração exógena dos reguladores vegetais é de extrema relevância, podendo favorecer ou não o enraizamento, o que pode não ter ocorrido no referido trabalho em virtude da temperatura, já que apresenta grande importância nas funções de regulação do metabolismo das plantas, afetando de forma positiva ou negativa o enraizamento (Cunha et al., 2009).

No presente experimento, devido da coleta das estacas ter sido feito no inverno, pode ter ocorrido dormência da planta, já que nesse período as plantas estão se preparando para entrar em dormência (Marangon et al., 2013). O enraizamento é influenciado pela duração $2 \mathrm{~d}$, uma vez que dias curtos associados às baixas temperaturas afetam negativamente nos processos de translocação de compostos e fotossíntese em virtude da inibição do ingresso de fosfatos nos cloroplastos das árvores matrizes, consequentemente, prejudicando o processo de enraizamento do material coletado nessas estações (Lawson et al., 2012).

Semelhante ao observado para o percentual de estacas vivas com calo e estacas mortas, o comprimento da raiz também foi significativamente afetado pelo aumento das concentrações de AIB observando-se, a partir da equação de regressão (Fig. 1G) comportamento linear, sendo obtido o comprimento máximo (4,7 cm) nas estacas tratadas com a concentração máxima (6.000 $\left.\mathrm{mg} \mathrm{L}^{-1}\right)$. Ao confrontar os dados obtidos nas estacas que foram tratadas com $6.000 \mathrm{mg} \mathrm{L}^{-1} \mathrm{em}$ relação às que estavam sob $0 \mathrm{mg} \mathrm{L}^{-1}$ de $\mathrm{AIB}$, constatase incremento de $54,46 \%$ no comprimento da raiz.

Estes valores são superiores aos observados por Rios et al. (2012), ao constatarem que o maior número de raiz foi de uma raiz por estaca de umbuzeiro, na concentração de $6000 \mathrm{mg} \mathrm{L}^{-1}$ de AIB. Os valores obtidos por Tosta et al. (2012) foram superiores aos encontrados neste trabalho ao verificarem máximo de 3,8 raízes por estaca de cajaraneira, na concentração máxima de $8545 \mathrm{mg} \mathrm{L}^{-1}$ de AIB.

Yamamoto et al. (2013) também não verificaram diferença significativa para o comprimento e numero de raízes por estaca quando as estacas de amoreira preta Xavante foram tratadas com AIB. Nacata et al. (2014), observaram em estacas de caramboleira, que a concentração de $5.000 \mathrm{mg} \mathrm{L}^{-1}$ influenciou positivamente o comprimento da raiz, enquanto que para o número de raízes a concentração de $100 \mathrm{mg} \mathrm{L}^{-1}$ apresentou os melhores resultados. Sabião et al. (2011), em Passiflora nitida observaram que o comprimento e o numero de raízes diferiram significativamente com o aumento das concentrações de AIB, obtendo os melhores resultados na concentração de $5.000 \mathrm{mg} \mathrm{L}^{-1}$, com os valores de 24,14 e 3,70, respectivamente.

Um dos parâmetros mais importantes para a qualidade das mudas é o comprimento das raízes e o número de raízes por estaca, uma vez que após a retirada das mudas da câmara de nebulização intermitente e levadas a campo um bom sistema radicular garante a sobrevivência das mesmas (Feldberg et al., 2010). Sendo assim, o uso de AIB é de extrema relevância, pois possibilita a rizogênese bem como induz a formação de um sistema radicular de qualidade, contudo, sua atuação varia conforme a espécie e a cultivar, podendo ainda estimular ou não o enraizamento, em virtude das concentrações endógenas de promotores (auxinas) e inibidores de enraizamento (Chagas et al., 2008; Bastos et al., 2009; Oliveira et al., 2010).

Os valores observados são superiores aos obtidos por Tosta et al. (2012) ao verificarem que o comprimento da raiz das estacas de cajaraneira aumentou até 1.295,2 $\mathrm{mg} \mathrm{L}^{-1}$ de AIB, sendo observado valor de 5,0 $\mathrm{cm}$, contudo, doses superiores promoveram decréscimo para esta variável.

Para o fator concentrações de AIB, o modelo de regressão no qual os dados obtiveram o melhor ajuste em termos de massa seca da raiz, folha e total foi o quadrático (Fig. 1H) constatando-se, na equação de regressão que o incremento nas concentrações de AIB proporcionaram um aumento na produção de massa seca, obtendo na concentração máxima (6.000 mg L-1) os valores máximos em massa seca da raiz (2,78 g), folha $(4,54 \mathrm{~g})$ e total $(8,39 \mathrm{~g})$.

Yamamoto et al. (2013) também não verificaram diferença significativa para o massa seca da raiz de estacas de amoreira preta Xavante foram tratadas com AIB. Para melhor desenvolvimento das mudas em campo, a maior massa de raízes influencia diretamente o desenvolvimento da muda, em virtude da maior capacidade de absorção de água e nutrientes (Santoro et al., 2010).

\section{CONCLUSÃO}

A aplicação de zinco em plantas matrizes de cajazeira não apresenta efeito sobre o enraizamento de estacas. 
A dose de $6.000 \mathrm{mg} \mathrm{L}^{-1}$ de ácido indolbutírico proporciona um incremento nas brotações, estacas vivas com calo, no entanto, não influencia no enraizamento.

Conflito de interesses: o manuscrito foi preparado e revisado com a participação de todos os autores, que declaram não ter qualquer conflito de interesses que possa afetar a validade dos resultados do trabalho apresentado.

\section{REFERÊNCIAS BIBLIOGRÁFICAS}

Alcantara, G.B., Y. Oliveira, D.M. Lima, L.A. Fogaça, F. Pinto e L.A. Biasi. 2010. Efeito dos ácidos naftaleno acético e indolilbutírico no enraizamento de estacas de jambolão [Syzygium cumini (L.) Skeels]. Rev. Bras. Plantas Med. 12(3), 317-321. Doi: 10.1590/ S1516-05722010000300009

Araújo, A.A.R., P.R.R. Silva, R.B. Querino, E.P.S. Sousa. e L.L. Soares. 2014. Moscas-das-frutas (Diptera: Tephritidae) associadas às frutíferas nativas de Spondias spp. (Anacardiaceae) e Ximenia americana L.(Olacaceae) e seus parasitoides no Estado do Piauí, Brasil. Semina: Ciênc. Agrár. 35(4), 1739-1750. Doi: 10.5433/1679-0359.2014v35n4p1739.

Bastos, D.C., J.A. Scarpare Filho, M.N. Libardi e R. Pio. 2009. Estiolamento, incisão na base da estaca e uso do ácido indolbutírico na propagação da caramboleira por estacas lenhosas. Ciênc. Agrotec. 33(1), 313-318. Doi: 10.1590/S1413-70542009000100043

Chagas, E.A., R. Pio, J.E. Bettiol Neto, G.D.R. Sobierajski, F.A. Campo Dall' Orto, e G. Signorini. 2008. Enraizamento de estacas lenhosas de pessegueiro e clones de umezeiros submetidos à aplicação de AIB. Ciênc. Agrotec. 32(3), 986-991. Doi: 10.1590/ S1413-70542008000300043

Cody, R. 2015. An introduction to SAS university edition. SAS Institute, Cary, NC.

Costa, E.M., A. Loss, H.P.N. Pereira e J.F. Almeida. 2015. Enraizamento de estacas de Bougainvillea spectabilis Willd. com o uso de ácido indolbutírico. Acta Agron. 64(3), 221-226. Doi: 10.15446/acag.v64n3.42970

Cunha, A.C.M.M., H.N. Paiva, A. Xavier e W.C. Otoni. 2009. Papel da nutrição mineral na formação de raízes adventícias em plantas lenhosas. Pesq. Flor. Bras. (58), 35-47. Doi: https://doi.org/10.4336/2009.pfb.58.35

Feldberg, N.P., W. Barbosa, N.A. Mayer e F.M.C. Santos. 2010. Propagação vegetativa de porta-enxertos de pereira por estacas semi-lenhosas. Rev. Ceres 57(6), 810816. Doi: 10.1590/S0034-737X2010000600017

Figueiredo, L.S., F.P.G. Bonfim, E.O. Ferraz, C.E. Castro, M.F. Souza e E.R. Martins. 2009. Influência do ácido indolbutírico no enraizamento de alecrim-pimenta
(Lippia sidoides) em leito com umidade controlada. Rev. Bras. Plantas Med. 11(1), 33-36. Doi: 10.1590/ S1516-05722009000100006

Gomes, W.A., M.A. Estrela, R.M.N. Mendonça, S.M. Silva, A.P. Souza, e R.E. Alves, 2005. Enraizamento de estacas de umbucajazeira (Spondias spp.). Proc. Interamer. Soc. Trop. Hortic. 47(1), 231- 233.

Lawson, T., D.M. Kramer e C.A. Raines. 2012. Improving yield by exploiting mechanisms underlying natural variation of photosynthesis. Curr. Opin. Biotechnol. 23(2), 215-220. Doi: 10.1016/j.copbio.2011.12.012

Lima, A.K.C., L.P. Rezende, F.A.A. Camara e G.H.S. Nunes. 2002. Propagação de cajarana (Spondias sp.) e cirigüela (Spondias Purpurea) por meio de estacas verdes enfolhadas, nas condições climáticas de Mossoró-RN. Caatinga 15(1/2), 33-38.

Marangon, M.A. e L.A. Biasi. 2013. Estaquia de mirtilo nas estações do ano com ácido indolbutírico e aquecimento do substrato. Pesq. Agropec. Bras. 48(1), 25-32. Doi: 10.1590/S0100-204X2013000100004

Meneguzzi, A., M.C. Navroski, Q.C. Lovatel, F.T. Marco, M.O. Pereira e E.L. Tonett. 2015. Ácido indolacético influencia no enraizamento de estacas de Pittosporum tobira. Rev. Ciênc. Agrovet. 14(1), 24-28.

Nacata, G., R.A.D. Andrade, S.P. Jasper e R.S. Prata. 2014. Propagação de variedades de caramboleira por estaquia herbácea. Rev. Bras. Frutic. 36(1), 248-253. Doi: 10.1590/0100-2945-237/13

Neves, L.C., J.M. Tosin, R.M. Benedette e L. Cisneros-Zevallos. 2015. Post-harvest nutraceutical behaviour during ripening and senescence of 8 highly perishable fruit species from the Northern Brazilian Amazon region. Food Chem. 174, 188-196. Doi: 10.1016/j. foodchem.2014.10.111

Nicoloso, F.T., M. Lazzari e R.P. Fortunato. 1999. Propagação Vegetativa de Platanus acerifolia Ait: (II) Efeito da aplicação de zinco, boro e ácido indolbutírico no enraizamento de estacas. Cienc. Rural 29(3), 487-492. Doi: 10.1590/S0103-84781999000300018

Oliveira, M.C., J.V. Neto, R. Pio, A.F. Oliveira e J.D. Ramos. 2010. Enraizamento de estacas de oliveira submetidas a aplicação de fertilizantes orgânicos e AIB. Ciênc. Agrotec. 34(2), 337-344. Doi: 10.1590/ S1413-70542010000200010

Paula, L.A., A.C. Boliani, L.S. Corrêa e M.I.B. Celoto. 2007. Efeito do ácido indolbutírico e raizon no enraizamento de estacas herbáceas e lenhosas de umbuzeiro. Acta Sci. Agron. 29(3), 411-414. Doi: 10.4025/actasciagron. v29i3.468

Peña, M.L., C. Gubert, M.C. Tagliani, P.M.C. Bueno e L.A. Biasi. 2012. Concentrações e formas de aplicação do ácido indolbutírico na propagação por estaquia dos mirtileiros cvs. Flórida e Clímax. Semina: Ciênc. Agrár. 33(1), 57-64. Doi: 10.5433/1679-0359.2012v33n1p57 
Rios, E.S., M.C. Pereira, L.S. Santos, T.C. Souza e V.G. Ribeiro. 2012. Concentrações de ácido indolbutírico, comprimento e época de coleta de estacas, na propagação de umbuzeiro. Rev. Caatinga 25(1), 52-57.

Sabião, R.R., A.C.C. Silva, A.B.G. Martins e E.R. Cardoso. 2011. Enraizamento de estacas de Passiflora nitida submetidas a diferentes concentrações de ácido indolbutírico (AIB). Rev. Bras. Frutic. 33(No. Spe. 1), 654-657. Doi: 10.1590/S0100-29452011000500091

Santoro, P.H., A.Y. Mikami, S.G.H. Souza e S.R. Roberto. 2010. Influência de folhas e lesões na base de estacas herbáceas no enraizamento de goiabeira da seleção 8501-9. Semina: Ciênc. Agrár. 31(2), 289-294. Doi: 10.5433/1679-0359.2010v31n2p289

Silva, F.V.G., S.M. Silva, G.C. Silva, R.M.N. Mendonça, R.E. Alves e A.L. Dantas. 2012. Bioactive compounds and antioxidant activity in fruits of clone and ungrafted genotypes of yellow mombin tree. Ciênc. Tecnol. Aliment. 32(4), 685-691. Doi: 10.1590/ S0101-20612012005000101

Souza, F.X. e R.N. Lima. 2005. Enraizamento de estacas de diferentes matrizes de cajazeira tratadas com ácido indolbutírico. Rev. Ciênc. Agron. 36(2), 189-194.

Souza, R.R., M.Z.B. Cavalcante, M.P.D. Lima, T.F. Alixandre e R.T. Nascimento, 2015. Propagação vegetativa de hibisco com diferentes tipos de estacas e concentrações de ácido indolbutírico. Comun. Sci. 6(3), 291296. Doi: 10.14295/cs.v6i3.679

Tosta, M.S., C.V.F. Oliveira, R.M.O. Freitas, V.C.N. Porto, N.W. Nogueira e P.A.F. Tosta. 2012. Ácido indolbutírico na propagação vegetativa de cajaraneira (Spondias sp.).
Semina: Ciênc. Agrár. 33(Supl. 1), 2727-2740. Doi: 10.5433/1679-0359.2012v33Sup11p2727

Véras, M.L.M., R.M.N. Mendonça, C.M.C. Ramires, S.M. Silva e W.E. Pereira. 2017. Effect of ethephon and indolebutyric acid on yellow mombin propagation via cutting. Pesqui. Agropecu. Trop. 47(4), 416-423. Doi: 10.1590/1983-40632017v4749515

Véras, M.L.M., R.M.N. Mendonça, S.M. Silva, L.F. Figueiredo, V.L. Araujo, W.E. Pereira, J.S.M. Filho e R. Andrade. 2018a. Propagation of umbuzeiro (Spondias tuberosa Arr. Cam.), a native plant to Brazilian semi-arid regions, using ethephon and indolebutyric acid (IBA). Aust. J. Crop Sci. 12(4), 602-609. Doi: 10.21475/ ajcs.18.12.04.pne888

Véras, M.L.M., R.M.N. Mendonça, L.F. Figueredo, V.L. Araújo, J.S. Melo Filho e W.E. Pereira. 2018b. Enraizamento de estacas de umbuzeiro potencializado pela aplicação de ácido ácido indol-3-butírico (AIB). Rev. Bras. Ciênc. Agr. 13(3), 1-9. Doi: 10.5039/agraria.v13i3a5541

Véras, M.L.M., R. Andrade, L.F. Figueredo, V.L. Araujo, J.S. Melo Filho, R.M.N. Mendonça e W.E. Pereira, 2018c. Uso de reguladores vegetais na propagação via estaquia de umbu-cajazeira. Rev. Ciênc. Agr. 41(3), 161170. Doi: 10.19084/RCA17153

Yamamoto, L.Y., R. Koyama, W.F.S. Borges, L.E.C. Antunes, A.M. Assis e S.R. Roberto. 2013. Substratos no enraizamento de estacas herbáceas de amora-preta Xavante. Ciênc. Rural 43(1), 15-20. Doi: 10.1590/ S0103-84782012005000135 